\title{
MÁS SABE EL DIABLO POR VIEJO..D PERO DEBEMOS INVESTIGAR
}

\section{M.Sc. Rolando Quesada Sancho*}

\begin{abstract}
Resumen: Las experiencias universitarias parecen estar limitando las posibilidades de fortalecer los nexos con la comunidad, este clivaje está promoviendo que la investigación se debilite. Esta situación es preocupante porque tiende a reorientar los fines y principios de la institución.

Por otro lado, ese debilitamiento repercute en las prácticas educativas, $y$ ha permitido desde la transferencia de conocimientos alienantes hasta privilegiar la atención en las didácticas como instrumentos, como ejercicio transmisor, entre otros. De manera que ante la ausencia de investigación, se instalan prácticas educativas que repiten contenidos de saberes asépticos y enajenadores, y los docentes (hombres y mujeres) se convierten en mediadores innecesarios. Esto nos plantea la exigencia de renovar el diálogo con nuestras realidades, con las y los hacedores de historias, mediante el fortalecimiento de la investigación y la acción social.

La universidad debe de prestar más atención en desarrollar un lenguaje crítico, que devele los intereses que históricamente han sustentado las disciplinas, así como las relaciones entre ellas y el currículo que reproduce y legitima la cultura dominante. Esto plantea la posibilidad de romper los límites con el fin de promover métodos de investigación alternativos, donde se incluyan los intereses que afirman la importancia política y normativa de la historia, la ética y la integración social. A la vez debe cuestionar aquellos factores que defienden las relaciones de dominación de algunas disciplinas y departamentos.
\end{abstract}

Palabras clave: INVESTIGACIÓN/ ENSEÑANZA SUPERIOR/ ACCION SOCIAL/ PRACTICAS EDUCATIVAS/ PRACTICAS SOCIALES/RELACIONES ESCUELA COMUNIDAD/

Abstracts: The university experiences seem to be limiting the possibilities of fortifying the nexuses with the community, this clivaje is promoting that the investigation is debilitated. This situation is worrisome because it tends to reorient the aims and principles of the institution.

On the other hand, that weakening repels in the educative practices, and has allowed from the transference of alienantes knowledge to privileging the attention in the didactic ones like instruments, like transmitting exercise, among others. So that before the investigation absence, educative practices settle that repeat aseptic and enajenadores contents of saberes, and the educational ones (men and women) turn unnecessary mediators.

This raises the exigency to us to renew dialogue with our realities, and the hacedores of histories, by means of the fortification of the investigation and the social action.

Tthe university must pay more attention in developing to a critical language, that reveals the interests that historically have sustained the disciplines, as well as the relations among them and currículo that the dominant culture reproduces and legitimizes. This raises the possibility of breaking the limits with the purpose of promoting alternative methods of investigation, where the interests are included that affirm the political and normative importance of history, the ethics and social integration. Simultaneously it must question those factors that defend the relations of domination of some disciplines and departments.

Key words: INVESTIGATION/ SUPERIOR EDUCATION/ SOCIAL ACTION/ PRACTICE EDUCATIVE/ PRACTICE SOCIAL/ RELATIONS SCHOOL COMMUNITYI

* Máster en Ciencias Sociales con mención en Educación, FLACSOArgentina. Docente-investigador del Instituto de Investigaciones para el Mejoramiento de la Educación Costarricense de la Universidad de Costa Rica (IIMEC) y Funcionario del Centro Nacional de Recursos para la Inclusión Educativa. del Ministerio de Educación Pública (CNREI). rolandoq@,costarricense.cl y rolandoq@cariari.ucr.ac.cl

Artículo recibido: 26 de agosto, 2003

Aprobado: 24 de noviembre, 2003

${ }^{1}$ El título hace referencia al refrán popular "más sabe el diablo por viejo que por diablo" que puede significar que las personas adquieren saberes por la experiencia de vida, que no pueden ser adquiridos con los estudios formales. 


\section{Iniciando con dos productos}

Hace apenas una semana, recibí en mi casa a unas compañeras profesoras universitarias con quienes discutimos durante la tarde, algunos aspectos de la educación costarricense. En forma muy amistosa comenzamos a conversar entorno a lo que estábamos haciendo cada uno y una, por supuesto yo les comenté cómo marcha el programa del Centro Nacional de Recursos para la Inclusión Educativa, del Ministerio de Educación Pública y el derecho de todas las personas a tener acceso a una educación de calidad, además de nuestro posicionamiento acerca del rechazo de cualquier forma de discriminación. Esto abrió la llave para una ardua discusión.

Uno de los argumentos que las invitadas pusieron sobre la mesa fue ¿cuántos niños con problemas existían en el país? ante lo cual les aclaré que no se refiere a niños "con problemas", que se trata de atender la diversidad, con el fin de que todos y todas venzamos las barreras de participación y comunicación, donde todos y cada uno y una nos incluimos pero a la vez nos incluyen. Este argumento rigidizó la conversación, pues entonces me hablaron de "media", de "moda" de "normalidad", todos términos muy estadísticos con el fin de demostrar la productividad en números y justificar así el programa y como contrargumento decían que las personas con alguna discapacidad tenían que seguir recluidos en escuelas especiales, pues ellos no eran "normales". Ante esto les debatí el concepto de "normalidad" diciéndoles que quién decidía quién era normal y quién no, y que eso respondía a un concepto ideológico y político de los grupos hegemónicos. También insistí en que no se trata de atender personas con discapacidad, sino de atender las necesidades educativas de todas las personas.

La dirección que tomó la conversación llegó a cuestionar la ideología y las prácticas pedagógicas, una de ellas, quien más participación tuvo en la conversación, enfatizaba que una cosa era la ideología y otra muy diferente la pedagogía. Ante lo cual recomendé que cambiáramos de tema porque estábamos en veredas diferentes, y no nos íbamos a poner de acuerdo.

Luego, cuando se despidieron, quedé reflexionando al respecto y tratando de analizar el rumbo que sigue la formación universitaria, puesto que los tres somos docentes universitarios, una de las visitantes laboró hace unas décadas en una instancia que capacitaba en pedagogía universitaria. Debo confesar que me quedé muy preocupado, y 
pensé en el hipotético caso en que una persona fuera alumna de los tres simultáneamente, cuál sería la formación que estaríamos propiciando.

La reflexión anterior me llevó a repensar otro episodio. Hace unos decenios, conocí a una persona que me contó muy orgulloso que él nunca había utilizado un autobús, que siempre su padre lo había transportado a la escuela, luego al colegio y cuando ingresó a la Universidad de Costa Rica, se compró un automóvil. Así la historia, terminó la carrera de Economía, y fue contratado por el Instituto Costarricense de Electricidad (ICE). También era material de orgullo y contradicción con mi pensamiento, el hecho de que nunca había tenido ni la necesidad ni la curiosidad de visitar el Mercado Central o el BorbónĐ-esto lo afirmaba con desprecio por las personas que cotidianamente lo habitan-. Demás está decir que cuando yo le comenté que esos fueron los nichos que yo frecuentaba cuando estudiaba y ejercía el teatro y años después lo serían también como estudiante de Antropología, y en la actualidad los visitos porque significa un espacio donde se congrega parte de nuestras realidades marginales que luchan por sobrevivir, comenzó a deslegitimar mi formación.

Luego esa persona, recibió una beca de una fundación que realizaba investigaciones y capacitación para lograr la paz y el progreso de la región, para realizar un posgrado en Inglaterra, cuya tesis de maestría versaba sobre las necesidades y urgencias de privatizar el ICE.

No existe un ligamen -de ningún tipo- entre los personajes mencionados, excepto que unas son profesoras y el otro fue estudiante de la misma universidad. Sin embargo pareciera que comparten la misma lógica. Las primeras parecen haberse quedado estacionadas en algún tracto del desarrollo del conocimiento, la otra parece no permitirse conocer la realidad social, económica, y cultural del país. Esto me lleva a preguntarme: ¿qué componentes académicos están favoreciendo en algunos y algunas profesionales, esas dinámicas esquizofrénicas ante la sociedad?

Consideramos que los factores que confabulan para la construcción de tales lógicas, son múltiples y esto lleva a un estudio en profundidad, sin embargo trabajaremos en este ensayo el supuesto de que las prácticas investigativas de los y las docentes los llevan a aprender y

\footnotetext{
${ }^{2}$ Ambos mercados, el primero con una fuerte orientación hacia la venta de comidas preparadas autóctonas y vestuario en general, con algunos expendios da abarrotes, el segundo especializado en la venta de verduras y abarrotes. Los dos mercados se encuentran en el centro de San José.
} 
aprehender mientras se investiga, y en esa práctica se aprende y se enseña simultáneamente, participando de una lógica dialéctica, de modo que esos saberes desbordan luego el objeto de investigación.

Para esta discusión he consultado a algunos autores cuyo pensamiento aportó en forma evidente en la posterior conformación de la corriente de la teoría crítica, como Martín-Baró y Freire, luego me fundamento en los representantes más divulgados de dicha teoría. Con esto no pretendo disminuir los valiosos aportes de otros y otras autoras que también han hecho su aporte al interior de nuestro país.

\section{La ruptura del diálogo}

Los episodios citados, sustentan la premisa de que la falta de investigación, o bien la investigación que no logra captar las representaciones que elaboran las personas, tiende a excluir de los espacios académicos, parte de los saberes que constituyen una realidad.

Como bien lo dice Paulo Freire "subestimar la sabiduría que resulta necesariamente de la experiencia socio-cultural es al mismo tiempo un error científico y expresión inequívoca de la presencia de una ideología elitista" (Freire, 1999, p. 81).

Al limitarse la entrada a una parte de los saberes, podemos encontrar que en las instituciones educativas y universitarias en particular, se reflejan los planteamientos de una de esa minoría a la cual se refiere Freire, donde "los valores oprimidos de nuestro campesino, nuestro indígena, nuestro obrero no encuentran eco" (Martín-Baró, 1979, p. 25).

Con lo anterior el visionario autor Jesuita, nos dibujó desde hace al menos dos décadas, la universidad que vivimos en la actualidad. Una institución que rompió el diálogo con la sociedad. "Con la sociedad y no con una capa social de ella", como dice él. Tal ruptura ha significado entre otras cosas, cambiar el sentido originario de la institución y abdicar, al menos parcialmente, a los fines y principios de la universidad. Permitiendo el ingreso a nuestras aulas, prácticas de aprendizajes foráneas, que resultan ser alienadoras, (MartínBaró, 1979).

La ruptura del diálogo con la sociedad, queda reflejado claramente en los episodios descritos al inicio, que ha llevado a más de una persona, a adoptar posicionamientos pragmáticos y 
acríticos, cuyos resultados los podemos observar en la toma de decisiones, donde privan resoluciones ajenas a nuestras necesidades sociales, económicas y culturales.

Dicha ruptura, para nada implica que la universidad elabora un monólogo para seguir sobreviviendo, por el contrario establece canales dialógicos con otros actores sociales, como es el mercado, cuya relación exige una reconfiguración axiológica de la formación profesional. En esta nueva orientación del diálogo aceptamos también "valores como el individualismo, la competencia, la genitalidad, la violencia, el culto al consumo y a las apariencias" (Martín-Baró, 1979, p. 27), que confabulan contra nuestras identidades educativas y culturales, que desde luego de ser apropiados en la academia se reproducen en el entorno social.

Así la lectura del mundo tiende a acotarse u orientarse, según intereses foráneos y del mercado, no permitiendo descodificar el contexto histórico, social, político y cultural de donde la institución es parte y la define, estableciéndose puntos contradictorios entre la realidad académica y la cotidiana, de manera que la relación con las clases populares, aquellas que no están representadas en el "texto académico", adquiere características impositivas. Esto es producto también del posicionamiento hegemónico que ha tenido la idea de que ahora se necesita una educación no tan comprometida, con la comprensión crítica del mundo, sino una educación al servicio de la capacitación estrictamente técnica (Freire, P., 1999).

Las consecuencias en las prácticas educativas son múltiples, desde la transferencia de conocimientos alienantes, como ya anotamos, hasta centrar la atención en las didácticas como instrumentos, como ejercicio transmisor, entre otros. De manera que ante la ausencia de investigación, se instalan prácticas educativas que repiten contenidos de saberes asépticos y enajenadores, y los docentes (hombres y mujeres) se convierten en mediadores innecesarios que hasta pueden ser sustituidos por un libro, sin que varíe la realidad educativa. (Martín-Baró, 1979).

La reificación docente, pasa a ser una característica propia de quien no se ha apropiado de la práctica de investigar, como un componente inmanente del quehacer docente, su comportamiento por lo tanto no logra ser autónomo, obstaculizando así toda vía que busque la liberación. Esto por supuesto, expresa sentimientos, actitudes, acriticidad, marcos conceptuales y axiológicos, entre otros, que el estudiante aprehende. En consecuencia, se 
limitan las opciones de crear y recrear el conocimiento desde nuestras realidades y no nos queda otra alternativa que apropiarnos de conocimientos que le pertenecen a otras realidades con otras necesidades, propiciando una docencia alienada, y consolidando el círculo de reproducción ideológica, pues como dice Martín-Baró “Una docencia será alienada en la medida en que la conducta de profesor y alumno esté determinada por mecanismos ajenos a ellos" (Martín-Baró, 1979, p. 46).

Sin investigación, la docencia no puede proporcionar esquemas cognoscitivos, contenidos teóricos y metodológicos novedosos y coherentes con las realidades que vivimos cotidianamente, por el contrario se tiende a reproducir los recursos didácticos de referencia como hemos anotado, que responden a problemas extraños a nuestras culturas, como las lecturas obligadas y complementarias, ejemplos ilustrativos, entre otros. De esa manera los contenidos que se desarrollan en el espacio áulico, terminan por apoyar la ruptura del diálogo con el entorno social propio. Así, el y la académica se anclan en las estructuras establecidas, sin proponer cambios, lo que constituye parte de la formación que los y las estudiantes experimentan en el paso por las universidades que luego, una vez profesionales, reproducen en escala nacional para abonar al círculo de reproducción ideológica.

Siguiendo a Martín-Baró, se debe tener presente que "es el profesor la imagen modélica más inmediata que el estudiante tiene sobre lo que debe ser o no un profesional y que es el profesor el que lleva a la práctica o bloquea la puesta en marcha de los procesos concientizadores" (1976, p. 114).

La abstención de realizar investigación, ha llevado a las instituciones a caer en un marasmo académico y a la vez ha permitido a los gobiernos y organismos internacionales a cuestionar la calidad de la educación y proponer la reorientación de los presupuestos. El escenario se compone de muchos elementos que cada persona los prioriza según su experiencia e intereses. De esta forma, presupuesto, tiempo, apoyo institucional, desidia, entre otros, son justificaciones que cotidianamente escuchamos, para no hacer investigación. Y por supuesto al no existir la investigación como práctica en la cultura académica, limita las posibilidades de reflexionar sobre la práctica docente y de ejercer una docencia acorde con las necesidades de la sociedad, en procura de una transformación de las condiciones sociales, políticas, económicas y culturales, donde se viva al amparo de los derechos humanos. Es en la ruptura dialógica, donde descansa parte de la inmediatez de la docencia universitaria. 


\section{La restauración del diálogo}

Una de las vías de la reconstrucción del diálogo con la sociedad es entonces propiciando la investigación, esto redunda en una pedagogía horizontal, donde los saberes de la sociedad tendrían espacio en la academia. Por otro lado con la investigación se recrean las verdades sociales y se reconstruye el conocimiento y los valores propios.

Sin embargo, no todo proceso investigativo nos lleva a los mismos propósitos, debemos estar claros que no todos pretenden una transformación, una liberación de los estados coloniales y alienados en que nos encontramos. Por el contrario, los propósitos de muchas investigaciones pretenden consolidar esas situaciones dominantes y autoritarias, como aquellas que tienen un sustrato positivista, que pretende aislar al sujeto investigador del sujeto de investigación, creando una falsa asepsia científica.

Tal como nos recuerda el antropólogo Peter McLarem, en el prefacio del Libro de H. Giroux: "Los profesores como intelectuales", al decir que

el profesor debe comprometerse en las siguientes tareas: la enseñanza como práctica emancipadora, la creación de escuelas como esferas públicas democráticas, la recuperación de una comunidad de valores progresistas compartidos y el fomento de un discurso público común unido a imperativos democráticos de igualdad y justicia social (Giroux, 1990, p. 20).

Este recordatorio, aun cuando el autor lo dirige a profesores y profesoras de escuelas públicas, lo podemos extrapolar y pensarlo para las universidades, que como podemos inferir de las anécdotas iniciales, la carencia de investigación nos lleva a frecuentar posiciones alejadas y poco comprometidas con la justicia social. Lo cual sucede, según nuestra perspectiva, porque persisten las relaciones asimétricas entre los contextos cotidianos y académicos. Estableciéndose tanto clivajes como rupturas entre ambos, exigiendo nuevas formas de relacionarnos y de conocernos.

Con la restauración del diálogo se puede resignificar tanto al y la docente como el sentido de la Universidad pues en tanto generadora de cultura, debe estar abierta al pueblo, conocer y responder a sus necesidades, de modo que como bien dice Martín-Baró, "es necesario que su vivencia, sus problemas sus necesidades, sus personas se hagan presentes en la Universidad" (1979, p. 34). 
También tenemos que considerar que para cambiar el rumbo de la historia, es necesario conocer por qué se vive de una manera y no de otra, y cuales son las cuestiones que sustentan esas realidades, lo que nos lleva a reflexionar acerca de la educación y sus relaciones con la conformación de la estructura económica, social y cultural.

De ahí que adherimos a Giroux en su observación de que

el discurso curricular debería tomar en serio las particularidades sociales e históricas que constituyen las formas y los límites que dan sentido a las vidas de los estudiantes y de otras personas que están en período de aprendizaje...[lo que] indica la necesidad de desarrollar teorías, formas de conocimiento y prácticas sociales que actúen en combinación con las experiencias que aportan las personas al marco pedagógico (Giroux, 1990, p. 185).

Esto nos plantea la exigencia de renovar el diálogo con nuestras realidades, con las y los hacedores de historias, mediante el fortalecimiento de la investigación y la acción social, áreas que han experimentado serias debilidades y que en algunos casos se mantienen falsamente. Esto lo anotamos porque la experiencia, por lo menos en la Universidad de Costa Rica, la estructura de poder, tanto interna como externa, favorece un tipo de investigación que lejos de estimular transformaciones consolida las estructuras dadas, mientras la acción social ha estado históricamente marginada. Recordemos que hasta hace muy poco, después de tres décadas, se discutía acerca del reconocimiento que debía tener la acción social, para ascender en Régimen Académico

La universidad parece fortalecer una serie de relaciones con los grupos dominantes que como bien dice Giroux, dicha institución "goza de una autonomía relativa, actúa ampliamente como una instancia de producción y legitimación de los conocimientos, habilidades y relaciones sociales que caracterizan las relaciones de poder dominantes en la sociedad" (Giroux, 1990, p. 207).

\footnotetext{
${ }^{3}$ Se refiere a los parámetros de ascenso para aquellos profesores y profesoras que son propietarias de sus plazas, condición que paulatinamente está entrando en desuso, por múltiples motivos, uno de ellos es el ejercicio del poder. Los profesores y profesoras tienen salarios mínimos, sin derecho a voto en las Asambleas de Facultad o de Escuela, entre otros.
} 
La universidad debe de prestar más atención en desarrollar un lenguaje crítico, que devele los intereses que históricamente han sustentado las disciplinas, así como las relaciones entre ellas y el currículo que reproduce y legitima la cultura dominante. Esto abre los cercos para promover métodos de investigación contestatarios, donde se incluyan los intereses que afirman la importancia política y normativa de la historia, la ética y la integración social. Asimismo debe cuestionar aquellos factores que defienden las relaciones de dominación de algunas disciplinas y departamentos.

Deben desarrollar métodos que investiguen cómo las ausencias y los silencios estructurados actuales que gobiernan la enseñanza, la vida académica y la administración dentro de los departamentos académicos niegan el nexo entre conocimiento y poder, reducen la cultura a un objeto incuestionado de dominio y no quieren reconocer el particular estilo de vida que el discurso académico dominante ayuda a producir y legitimar. (Giroux H., 1990, p. 207).

El lenguaje no se resignifica sin una base científica, por el contrario es necesaria la investigación para reconstruir significados, esto por supuesto debe de hacerse con un sentido crítico, a partir de la propia realidad y a la luz de la justicia social, que nos permita retrotraer cuerpos teóricos para interpretar nuestras cotidianidades y poder transformarlas. La criticidad es indispensable pues como bien lo afirma Giroux, la teoría no solo reestructura la interpretación personal sino que reproduce realidades sociales e históricas, de modo que la teoría es crucial para todos los niveles de pensamiento (Giroux, 1990).

El anquilosamiento intelectual, parece reafirmarse con la ruptura del diálogo y la ausencia de investigación, como lo reflejan los posicionamientos de las personas aludidas al inicio, que siguen creyendo que las personas con discapacidad deben permanecer segregadas, cuando el desarrollo de las corrientes de pensamiento sociológico y cultural, proponen la inclusión en todos los espacios de nuestra existencia, no solo de ellas sino de todas las personas. Por otro lado tales posicionamientos acríticos, evidencian que el pensamiento es dinámico, y cambia según los momentos históricos que se experimenten.

Es necesaria la confrontación dialéctica personal y comunitaria, con la realidad social, que nos permita promover y proponer cambios, de modo que es mediante la concienciación, que se logra practicar y asumir la dialéctica de praxis y reflexión que enfrenta al hombre y mundo (Martín-Baró, 1979). Proceso que por otro lado está conformado por una serie de 
componentes culturales, sociales, que hace que se manifieste eminentemente como un proceso político y al que se puede acceder mediante la investigación.

De modo que si queremos una educación que respete las cosmovisiones de los y las dicentes y que los desafíe a pensar críticamente, y que el pensar en forma pertinente sea un componente inherente de los procesos de enseñanza y aprendizaje, exige la capacitación permanente de los educadores y educadoras. Como bien dice Freire "su capacitación científica exige un serio y coherente empeño con miras a superar las viejas marcas autoritarias y elitistas que perduran en las personas, que "habitan" en ellas, siempre prontas a ser reactivadas" (Freire, 1999, p. 165).

\section{El diálogo permanente}

Subyace en lo expuesto, que el restablecimiento del diálogo tiene un propósito emancipatorio, que pretende promover transformaciones en la práctica social para mejorar la vida concreta, con lo cual se transforma la conciencia. Ambas, práctica social y conciencia, comportan una unidad dialéctica. Pareciera que este diálogo resulta ser el verdadero camino de la reflexión, aproximándose críticamente a la propia práctica que es donde se cristalizan los contenidos ideológicos, que orientan la acción, que pueden cambiar la conciencia, y que simultáneamente cambia la práctica social. De modo que el conocimiento del mundo, se inicia allí, con la toma de conciencia crítica acerca de la ubicación de cada uno en ese mundo.

En este proceso se transita de la curiosidad ingenua asociada al sentido común, que al hacerse crítica se orienta hacia la curiosidad epistemológica, que se caracteriza por su rigurosidad metodológica como condición sine qua non para acercarse al objeto cognoscible, (Freire, 1996).

Lo anterior porque "la tarea coherente del educador que piensa acertadamente es, mientras ejerce como ser humano la práctica irrecusable de entender, desafiar al educando con quien se comunica y a quien comunica, a producir su comprensión de lo que viene siendo comunicado" (Freire, 1996, p. 39). 
Es de esta manera como el educando, debe aprender a conocer y a conocerse, a la par de que el educador enseñe ciertos contenidos, debe retarlo para que, en su propia práctica se perciba como sujeto capaz de saber.

Concatenando lo anotado, para que un educador ejerza su profesión críticamente, es indispensable, comenzar por casa, es decir reflexionar en torno a su práctica en forma crítica, confrontándola con un sistema conceptual que le permita interpretarla para transformarla, y transformar la sociedad, esto no queda únicamente como un ejercicio individual sino que debe convertirse en un acto social y luego en actividad cotidiana.

Restablecer el diálogo, entonces no significa establecer lazos entre dos realidades donde se obvien los sujetos, por el contrario es la relación entre sujetos, intersubjetiva, con sus sentimientos, sus olores, sus sabores, sus colores, entre otros. Por eso el diálogo debe comenzar por un "diálogo consigo mismo" para aprehender mi lugar en el mundo, mi relación con la estructura económica, social, cultural y política donde habito.

Existen múltiples caminos para no seguir formando profesionales que establezcan relaciones esquizofrénicas con y en la sociedad. Esto claramente deja de lado la investigación técnica "que se aplica cuando un técnico organiza en una clase una actividad en función de cierto interés que él ha determinado, observa el proceso y saca sus conclusiones" (Barboza, 1998, p. 107).

Entre los métodos que han sido utilizados, está la etnografía educativa. Este método permite ingresar en las reconstrucciones simbólicas y las representaciones que los educadores y educandos elaboran en los procesos de enseñanza y aprendizaje. Así la etnografía adquiere relevancia en tanto, que da cuenta de las estructuras simbólicas que sustentan las manifestaciones aparenciales de las personas, sin embargo ella misma tiene sus propias limitaciones.

Los estudios etnográficos dan cuenta de la manera como opera el poder y como se reconfiguran los imaginarios pedagógicos, permite de alguna manera levantarle las enaguas o bajarle los pantalones al el hecho educativo, "desnudarlo" para lo cual el mismo investigador debe de "desvestirse" también, para que los lectores conozcamos sus sentimientos, su posicionamiento ideológico, su manera de aproximarse a esa realidad, entre 
otros, y en su escrito lo debemos sentir, oler, oír el latido de su corazón. Sin embargo, la debilidad que pueden tener los trabajos de etnografía educativa, es que el conocimiento lo aprehende en primera instancia el o la investigadora, que es la persona que interpreta la información, luego ella puede transferirla a los y las participantes en la investigación, para que realicen las transformaciones y ajustes necesarios, de acuerdo con sus propios intereses. Esta experiencia parece no permitir que las personas que promueven la investigación den seguimiento a sus hallazgos e interpretaciones de aquella realidad, en tanto que la utilización desborda el espacio de acción de quien investiga. También, no siempre el o la investigadora es parte del grupo social y cultural investigado, planteando otras limitaciones.

En lo que si estamos de acuerdo es que el conocimiento que adquiere el o la investigadora de la realidad, le debe permitir ejercer la docencia críticamente y esto lo debe transmitir a sus estudiantes, también la misma experiencia le provee de ciertos recursos que lo empoderan como docente, para compartir nuevos conocimientos, y transmitir un modelo de profesional comprometido con la realidad social, y contra cualquier forma de segregación, dominación, alineación.

La práctica de realizar etnografía educativa generalizada entre los docentes, puede dar excelentes resultados, pues el conocimiento se reconstruye desde las realidades mismas. Con base en las estructuras mentales de los y las estudiantes. Sin embargo, reiteramos, la interpretación de la información pareciera que queda a cargo de quien coordina el estudio. Las y los informantes o sujetos investigados, no participan en la reinterpretación de su propia realidad, acotando así las posibilidades de transformación. Esto no quiere decir que ellos no vayan a favorecerse del estudio, solo que no es autónomo, pues depende de las personas educadoras que eventualmente incorporen los nuevos conocimientos a sus prácticas docentes o bien que haya una devolución de resultados por parte de los y las investigadoras, mediante talleres, textos, capacitaciones, entre otros.

Carr y Kemmis manifiestan que "la ciencia educativa crítica, debe ser una ciencia participativa, donde profesores, estudiantes, y otros, crean, mantienen, disfrutan y soportan las disposiciones educativas" (1986,170). 
En este sentido, la investigación-acción es el otro método que permite a la comunidad educativa reflexionar sobre sus prácticas y concienciar todas las formas ideológicas que la alienan. El proceso comienza con la reflexión sobre las prácticas, acentuando el análisis de todos los términos que se utilicen pues ellos están cargados de sentidos ideológicos. Luego se planifica un curso en función de la modificación de esas prácticas alienantes, se actúa, es decir se lleva a la acción de aquello planificado, se observa la experiencia, se reflexiona sobre esa observación y a partir de ese momento recomienza el nuevo ciclo de planificación. Uno de los requisitos para que se den las condiciones adecuadas para este tipo de investigación, es que todos y todas las integrantes de la investigación-acción sean parte de ella, sean participantes del grupo. Mantener personas foráneas que coordinen, interpreten, observen, entre otros, niega cualquier intento emancipador, pues esta acción solo es posible si el grupo reflexiona acerca del sistema ideológico que determina sus prácticas alienadas. Un conocedor externo, no solo no puede lograr un nivel de aproximación a la realidad vivida, sino que en el acto de conocer, las y los sujetos no logran transmitir en su totalidad su vivencia, limitando así cualquier salida del estado alienado.

La trayectoria que hemos seguido nos impone la necesidad de volver a las posiciones esquizofrénicas que mantienen algunas personas que ejercen la docencia universitaria. Consideramos que la permanente reflexión sobre la práctica docente, un diálogo orgánico con la sociedad, proveen un escenario que es dinamizado por la investigación. Ella sin embargo debe aportar a la emancipación. De esta manera las y los profesionales que formemos lejos de proponer acciones que atentan contra la población, en favor de intereses individuales, buscarán formas alternativas de transformar la estructura económica, social, cultural y política, para que todos y todas tengamos acceso a un mundo mejor.

Esta es una de las maneras en que podemos reivindicar la misión de las universidades públicas, el deber ser de ellas, hemos dicho, es mantener un diálogo permanente con el pueblo, que es quien llena las aulas, con gustos diferentes, con costumbres, con rituales, con expectativas, con estímulos, en fin, diferentes. A esa diferencia es la que debemos formar académica y orgánicamente, con miras a reconstruir la realidad, favoreciendo a todas las personas, luego la experiencia podría reproducirse. Así construimos lo inédito viable. 


\section{Referencias}

Barboza, Oruam. (1998). Wilfred Carr y Stephen Kemmis. Teoría Crítica de la enseñanza. En: Servicio Paz y Justicia. Decenio de la educación en Derechos Humanos. Uruguay.

Carr, Wilfred. (1990). Hacia una ciencia crítica de la educación. Barcelona: Editorial Lertes.

Carr, Wilfred y Stephen Kemmis. (1988). Teoría crítica de enseñanza. La investigaciónacción en la formación del profesorado. Barcelona: Martínez Roca.

Freire, Paulo. (1997). Pedagogía de la autonomía, saberes necesarios para la práctica educativa. México: Siglo Veintiuno Editores, S.A. de C.V.

(1993). Pedagogía de la Esperanza, un reencuentro con la Pedagogía del Oprimido. México: Siglo Veintiuno Editores, S.A. de C.V.

(1994). Educación y participación comunitaria. En: Nuevas perspectivas críticas en educación. Barcelona: Ediciones Paidós.

Giroux, Henry. (1994) Jóvenes, diferencia y educación postmoderna. En: Nuevas perspectivas críticas en educación. Barcelona: Ediciones Paidós.

Giroux, Henry. (1990). Los profesores como intelectuales, hacia una pedagogía crítica del aprendizaje. Madrid: Centro de Publicaciones M.E.C. y Ediciones Paidós Ibérica.

Martín-Baró, Ignacio. (1979). Haciendo la Universidad. Guatemala: Cuadernos Universitarios FUPAC.

MacLaren, Peter. (1998). La escuela como un performance ritual, hacia una economía de los símbolos y gestos educativos. México: Siglo XXI Editores S.A.

. (1998). Pedagogía crítica: un panorama general. En: La vida de las escuelas, una introducción a la pedagogía crítica en los fundamentos de la educación. México: Siglo XXI Editores S.A. 